\title{
Ammonium-type Nitrogen Assimilation in Tea Plants
}

\author{
Tadakazu TAKEO \\ National Research Institute of Tea, Kanaya, Haibara, Shizuoka 428, Japan
}

Received December 3, 1979

\begin{abstract}
Ammonia supplied to tea roots was mainly stored as theanine, glutamine and arginine in roots and leaves before the sprouting of new shoots. These compounds were transferred to growing points (new shoots) when the tea plants began to grow after the resting period. Theanine, a remarkable amide in tea plants, was, especially, concentrated in the new shoots. The accumulation of theanine in new shoots was due not only to large transports from roots, but also to slow utilization in the new shoots.

L-Methionine-DL-sulfoximine (MSO) suppressed the reconstruction of ammonia into amino acids and amides, especially theanine. Furthermore, MSO inhibited the activity of glutamate synthase. However, the activity of glutamate dehydrogenase was not suppressed.
\end{abstract}

Many reports have been presented explaining the pathway of ammonia assimilation in plants. ${ }^{1,2)}$ Recently, it has been recognized that the incorporation of ammonia in plants is done through two enzyme pathways, the glutamate dehydrogenase system and the glutamine synthetase and glutamine-2-oxoglutarate-aminotransferase (glutamate synthase) system (GS-GOGAT system).

Many investigations have been reported on annual plants. ${ }^{3 \sim 7)}$ However, there are only a very few reports on perennial plants. The tea plant shows a remarkable nitrogen metabolism on ammonia assimilation, the synthesis of theanine, which is a characteristic amide in tea plants. It is also a remarkable property that the tea plant is highly adaptable to heavy application of ammonia, and theanine accumulates in tea plants supplied with an excess of ammonia.

I recently investigated the properties of glutamate dehydrogenase from tea rootlets incubated in some nitrogen sources, ${ }^{8)}$ and observed that the amination reaction of glutamate dehydrogenase increased with high concentrations of ammonia.

This paper deals with the changes of amino acid and amide contents in the tea plant, especially in tea roots after ammonia application under the conditions of short and long days at low and high temperatures. The GS-GOGAT system for ammonia assimilation of the tea plant is also speculated.

\section{MATERIALS AND METHODS}

Material and cultivation. A tea (Camellia sinensis, L.) cutting grown in the nursery bed for one year was replanted in a Wagner pot $(1 \mathrm{a} . / 5000)$ and cultured in a sand culture under nitrogen deficient conditions ${ }^{8)}$ for six months in a green house before the experiment. Tea seedlings were germinated in a moist sand bed for 50 days in the dark at $25^{\circ} \mathrm{C}$ and grown under light at an intensity of 15,000 lux at $25^{\circ} \mathrm{C}$ for another 30 days with supplying of water.

Treatment with ammonia. Tea cuttings were grown under illumination at an intensity of 15,000 lux for $8 \mathrm{hr}$ at $13^{\circ} \mathrm{C}$ and in the dark for $16 \mathrm{hr}$ at $5^{\circ} \mathrm{C}$ each day (the short day condition at low temperature) for 68 days after supplying $1 \mathrm{~g}$ of $\left(\mathrm{NH}_{4}\right)_{2} \mathrm{SO}_{4}$ per pot with $200 \mathrm{ml}$ of a culture medium containing $0.25 \mathrm{~mm} \mathrm{~K}_{2} \mathrm{HPO}_{4}$, $2.5 \mathrm{mM} \mathrm{KNO}{ }_{3}, 2.5 \mathrm{~mm} \mathrm{Ca}\left(\mathrm{NO}_{3}\right)_{2}, 1 \mathrm{~mm} \mathrm{MgSO}_{4}$ and $0.0001 \%$ Ferric citrate. The tea cuttings were then transferred to illumination at 15,000 lux for $14 \mathrm{hr}$ at $25^{\circ} \mathrm{C}$ and in the dark for $10 \mathrm{hr}$ at $20^{\circ} \mathrm{C}$ each day (the long day condition at high temperature) for another 50 days after application of another $1 \mathrm{~g}$ of $\left(\mathrm{NH}_{4}\right)_{2} \mathrm{SO}_{4}$. Each pot was supplied with $200 \mathrm{ml}$ of $\mathrm{H}_{2} \mathrm{O}$ every other day during the experimental period.

Treatment with ${ }^{15} \mathrm{~N}$-ammonia. Tea cuttings supplied with $1 \mathrm{~g}$ of ${ }^{15} \mathrm{~N}-\left(\mathrm{NH}_{4}\right)_{2} \mathrm{SO}_{4}\left(10 \%\right.$ excess of $\left.{ }^{15} \mathrm{~N}\right)$ at the beginning of the experiment were grown in a green house with supplying of $\mathrm{H}_{2} \mathrm{O}$.

Treatment with ${ }^{14} \mathrm{C}$-labeled compounds. ${ }^{14} \mathrm{C}$-Glutamate treated sample: Two cuttings were dipped in 
2 liters of a medium ( $\mathrm{pH} 6.0$ ) containing $14 \mathrm{mmol}$ of glutamate and $20 \mu \mathrm{Ci}$ of glutamate $\mathrm{U}^{14} \mathrm{C}$ (sa. $230 \mathrm{mCi} /$ mmol). ${ }^{14} \mathrm{C}$-Ethylamine treated sample: The cuttings were dipped in 2 liters of a medium containing $7 \mathrm{~m}$ moles of glutamate and ethylamine and $18 \mu \mathrm{Ci}$ of ethylamine- $1-{ }^{14} \mathrm{C}$ ( $\mathrm{sa} .9 .8 \mathrm{mCi} / \mathrm{mmol}$ ).

Each sample was incubated under 15,000 lux at $25^{\circ} \mathrm{C}$ for $48 \mathrm{hr}$. After washing the root part of samples, each sample was replanted in a Wagner pot $(1 \mathrm{a}, / 5000)$ and cultured in a sand culture for 30 days under light at 15,000 lux at $25^{\circ} \mathrm{C}$. Each pot was placed in a glass box equipped with a ventilating device and the exhaust gas from tea cuttings was absorbed in a alkali solution.

Treatment with L-methonine-DL-sulfoximine. Tea seedlings, from which the cotyledons were removed, were dipped in a medium containing $3.3 \mathrm{~mm} \mathrm{ATP}$ and $6.6 \mathrm{mM} \mathrm{MgSO}_{4}$ in $0.03 \mathrm{M}$ Tris- $\mathrm{HCl}$ buffer $(\mathrm{pH} \mathrm{7.4)} \mathrm{for}$ $24 \mathrm{hr}$. The seedlings were divided into two parts and each part was incubated in either a medium with or without $5 \mathrm{mM} \mathrm{L}$-methionine-DL-sulfoximine for another $24 \mathrm{hr}$. Then, each part was dipped in a $200 \mathrm{ppm} \mathrm{N}$ $\left(\mathrm{NH}_{4}\right)_{2} \mathrm{SO}_{4}$ medium ( $\mathrm{pH} \mathrm{5.5)}$ for $24 \mathrm{hr}$. The experiments were done under continuous illumination at $15,000 \mathrm{lux}$ at $25^{\circ} \mathrm{C}$.

Isolation and determination of ${ }^{14} \mathrm{C}$-amino acids and amides. ${ }^{14} \mathrm{C}$-Amino acids and amides in tea plants were isolated and the ${ }^{14} \mathrm{C}$ activities were determined by the previously reported methods. ${ }^{2}$ ?

Determination of ${ }^{15} \mathrm{~N}$-content. After each organ separated from a tea plant was lyophilized, the dried samples were subjected to ${ }^{15} \mathrm{~N}$ determination using an emission spectrometric ${ }^{15} \mathrm{~N}$ analyzer by the method reported by Kim et al. ${ }^{10)}$

Determination of amino acid. The samples were prepared by the previously reported process.1.1) Amino acids and amides were determined using an automatic amino acid analyzer equipped with a basic resin (LCR2) column and three elution buffers, $0.25 \mathrm{~N}$ Li-buffer $(\mathrm{pH} 2.7), 0.3 \mathrm{~N}$ Li-buffer $(\mathrm{pH} 3.15)$ and $1.3 \mathrm{~N} \mathrm{Li}$-buffer (pH 6.5).

Enzyme preparation. The enzyme solutions from tea rootlets of cuttings and seedlings were prepared by the previously reported method. ${ }^{8}$ )

Enzyme assay. The activity of glutamate dehydrogenase from tea rootlets was determined by the NADH assay, which measures the reductive amination, reported in the previous paper. ${ }^{5)}$ The activity of glutamate synthase in tea rootlets was assayed in a $3 \mathrm{ml}$ reaction mixture containing $300 \mu \mathrm{mol}$ of Tris- $\mathrm{HCl}$ $(\mathrm{pH} 8.0), 0.3 \mu \mathrm{mol}$ of NADH, $30 \mu \mathrm{mol}$ of $2-0 x$ oglutarate, $300 \mu \mathrm{mol}$ of $\mathrm{L}$-glutamine and enzyme solution after some modifications of the method by Duke et al. ${ }^{12)}$ The activity was monitored by measuring NADH oxidation at $340 \mathrm{~nm}$ at $30^{\circ} \mathrm{C}$.

\section{RESULTS AND DISCUSSION}

\section{Accumulation of ${ }^{15} \mathrm{~N}$ in a tea plant}

The dry weights of rootlets gradually increased during the incubation period, as shown in Table I. Those of the main roots and trunks did not show any obvious changes. New shoots sprouted out 25 days after supplying with ${ }^{15} \mathrm{~N}$-ammonium and grew to 56 days.

Table I. Changes of Dry Weight of Tea Plants

( $\mathrm{g}$ of three plants)

\begin{tabular}{lrrr}
\hline & Start & 25 days & 56 days \\
\hline Rootlet & 13.9 & 14.0 & 15.0 \\
Main root & 15.0 & 14.0 & 17.5 \\
Trunk & 17.1 & 16.9 & 17.0 \\
Stalk & 1.5 & 4.2 & 4.1 \\
Matured leaf & 10.6 & 10.5 & 11.2 \\
New shoot & - & 0.075 & 4.2 \\
\hline
\end{tabular}

In the nitrogen deficient tea plants, the newly supplied nitrogen was transported to trunk and matured leaf parts in 5 to 12 days from the root part, as shown in Table II.

Table III shows the amounts of the newly supplied nitrogen fraction calculated from ${ }^{15} \mathrm{~N}$ excess percentage in the total nitrogen and the stored old nitrogen fraction accumulated in each organ of a tea plant prior to the application of ${ }^{15} \mathrm{~N}$-ammonia, and the ratios between both the nitrogen fractions. After 25 days of ${ }^{15} \mathrm{~N}$-ammonia application, new shoots sprouted. The nitrogen accumulated in roots begun to shift to the terrestrial parts of the tea plant. The transference of the newly absorbed nitrogen fraction to the matured leaves and new shoots was stimulated. Furthermore, the stored old nitrogen in roots and matured leaves was also shifted to stalks, trunks and new shoots. In the new shoots, the contents of newly absorbed nitrogen and the stored old nitrogen were in the ratio of two to one.

From these results, it was considered that some of the stored nitrogen in roots and matured leaves was transported to young stalks and 
Table II. Changes of the Contents of Newly Supplied Nitrogen and Stored Old Nitrogen in Tea Plants

(N \% in dry matter)

\begin{tabular}{|c|c|c|c|c|c|c|}
\hline & Rootlet & Main root & Trunk & Stalk & Matured leaf & New shoot \\
\hline Start & 0.74 & 0.48 & 0.35 & 0.76 & 1.64 & - \\
\hline \multicolumn{7}{|l|}{5 days } \\
\hline New & 0.11 & 0.08 & 0.10 & 0.06 & 0.25 & - \\
\hline Old & 0.74 & 0.40 & 0.42 & 0.74 & 1.50 & - \\
\hline Total & 0.85 & 0.48 & 0.52 & 0.80 & 1.75 & - \\
\hline \multicolumn{7}{|l|}{11 days } \\
\hline New & 0.20 & 0.10 & 0.15 & 0.15 & 0.55 & - \\
\hline Old & 0.74 & 0.40 & 0.46 & 0.66 & 1.50 & - \\
\hline Total & 0.94 & 0.50 & 0.61 & 0.81 & 2.05 & - \\
\hline \multicolumn{7}{|l|}{25 days } \\
\hline New & 0.41 & 0.12 & 0.20 & 0.20 & 1.00 & 2.85 \\
\hline Old & 0.82 & 0.37 & 0.45 & 0.64 & 1.40 & 1.35 \\
\hline Total & 1.23 & 0.49 & 0.65 & 0.84 & 2.40 & 4.20 \\
\hline \multicolumn{7}{|l|}{56 days } \\
\hline New & 0.36 & 0.10 & 0.18 & 0.29 & 0.75 & 1.60 \\
\hline Old & 0.54 & 0.30 & 0.44 & 0.54 & 1.25 & 0.70 \\
\hline Total & 0.90 & 0.40 & 0.62 & 0.83 & 2.00 & 2.30 \\
\hline
\end{tabular}

Table III. Ratios Between Newly Supplied Nitrogen and Stored Old Nitrogen in Tea Plants

( $N$ mg in three plants)

\begin{tabular}{|c|c|c|c|c|c|c|c|c|}
\hline & \multicolumn{8}{|c|}{ After ${ }^{16} \mathrm{~N}-\left(\mathrm{NH}_{4}\right)_{2} \mathrm{SO}_{4}$ Application } \\
\hline & \multicolumn{2}{|c|}{ Start } & \multicolumn{3}{|c|}{25 Days } & \multicolumn{3}{|c|}{56 Days } \\
\hline & Old & Total & New & Old & Total & New & Old & Total \\
\hline Rootlet & 103 & 103 & 57 & 115 & 172 & 50 & 82 & 132 \\
\hline Main root & 72 & 72 & 17 & 52 & 69 & 17 & 51 & 68 \\
\hline Trunk & 59 & 59 & 34 & 76 & 110 & 31 & 74 & 105 \\
\hline Stalk & 11 & 11 & 8 & 28 & 36 & 11 & 23 & 34 \\
\hline Matured leaf & 172 & 172 & 106 & 145 & 251 & 95 & 140 & 235 \\
\hline New leaf & - & - & 21 & 10 & 31 & 67 & 29 & 96 \\
\hline Total & 417 & 417 & 243 & 426 & 669 & 271 & 399 & 670 \\
\hline Ratio $(\%)$ & 100 & & 36 & 64 & & 40 & 60 & \\
\hline
\end{tabular}

new shoots after sprouting of new buds.

Effect of light and temperature on ammonia assimilation

Figure 1 shows the level fluctuations of amino acids and amides in tea plants grown under the conditions of the short day at low temperature and the long day at high temperature.

Under the short day condition, tea plants were in the resting stage. In the resting period, the ammonia absorbed into tea roots was mainly synthesized to theanine, glutamine and arginine, which are abundant in tea plants, and accumulated in each organ in the tea plant. Especially, a high content of theanine was stored in rootlets. Glutamine was mainly accumulated in root parts. Arginine was universally distributed in the tea plant.

These results show that an ammonia-type fertilizer was absorbed and still constructed into glutamine, theanine and arginine in tea rootlets in the resting stage under the experimental conditions and these amino compounds 


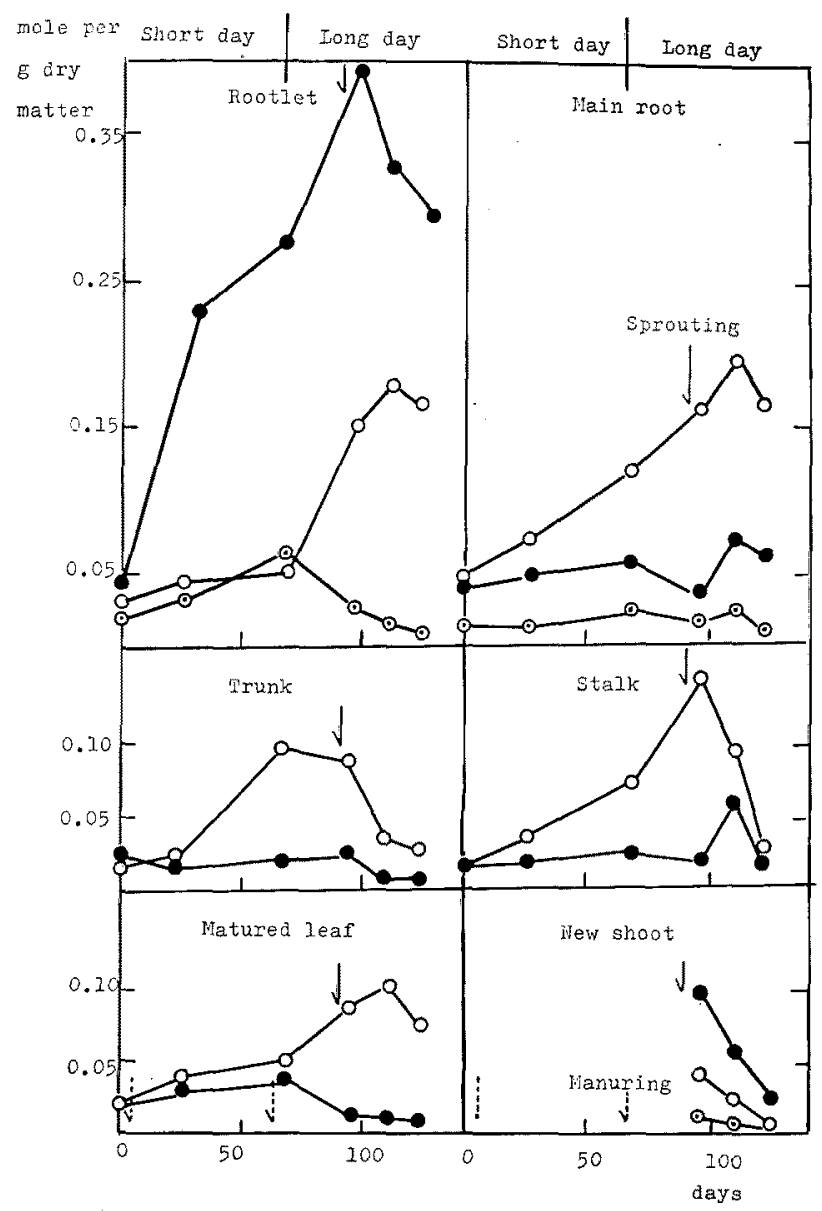

FIG. 1. Changes of the Concentrations of Amino Acids in Tea Plants.

$\bullet$, theanine; $\odot$, glutamine: 0 , arginine; $\longrightarrow$, sprouting; $\rightarrow-\rightarrow$, manuring.

were stored in each part of the tea plant.

The tea plants cultured under the short day condition for 68 days were supplied again with ammonia and transferred to the long day condition. The tea plants began to grow immediately after transference and sprouted after 25 days.

The contents of glutamine in the rootlets and theanine in the terrestrial parts decreased rapidly under the long day condition. However, the contents of arginine in the terrestrial parts were maintained at the high levels until new shoots sprouted, and began to decrease after sprouting.

The contents of theanine and arginine in the rootlets and roots continued to increase until sprouting of new shoots by absorbing supplied ammonia. However, the contents of these compounds in the rootlets also decreased after sprouting. It is thought that these compounds might be mainly transported to the new shoots, because they were maintained at high contents in the new shoots in the early developing stage.

From these results, it is thought that theanine, glutamine and arginine are the stored nutrients of the tea plant in the resting stage, and these compounds stored in tea root parts were transported to the growing points when tea plant started to grow. Especially, it is noticeable that theanine is concentrated in new shoots. 
Table IV. ${ }^{14}$ C-Activity Changes in Amino Acids and Amides $\left(10^{4} \mathrm{cpm}\right.$ per two plant parts)

\begin{tabular}{|c|c|c|c|c|c|}
\hline & \multirow[b]{2}{*}{ Fraction } & \multicolumn{2}{|c|}{ After 2 days } & \multicolumn{2}{|c|}{ After 30 days } \\
\hline & & Root & Leaf & Root & Leaf \\
\hline \multirow{3}{*}{$\begin{array}{l}{ }^{14} \mathrm{C} \text {-Glutamate } \\
\text { treated plant }\end{array}$} & Theanine & 0.40 & 0.20 & 0.15 & 0.10 \\
\hline & Glutamine & 2.00 & 0.35 & 0.40 & 0.15 \\
\hline & Glutamate & 0.60 & 0.25 & 0.05 & 0.05 \\
\hline \multirow{3}{*}{$\begin{array}{l}{ }^{14} \mathrm{C} \text {-Ethylamine } \\
\text { treasted plant }\end{array}$} & Theanine & 3.95 & 0.35 & 1.38 & 1.00 \\
\hline & Glutamine & 1.50 & 0.20 & 0.40 & 0.10 \\
\hline & Glutamate & 0.25 & 0.15 & 0.07 & 0.05 \\
\hline
\end{tabular}

\section{Rates of theanine and glutamine dissimilation in tea plants}

When tea cuttings were supplied with ${ }^{14} \mathrm{C}$ glutamate and ${ }^{14} \mathrm{C}$-ethylamine through the roots, the former was mainly constructed into ${ }^{14} \mathrm{C}$-glutamine and the latter into ${ }^{14} \mathrm{C}$-theanine, respectively. Before and after 30 days incubation in a green house, the distributions of the ${ }^{14} \mathrm{C}$ activity in the amino acid fractions were assayed in the roots and leaves.

In ${ }^{14} \mathrm{C}$-glutamate treated plants, the ${ }^{14} \mathrm{C}$ activities in the amino acids were mostly diminished after 30 days incubation. In ${ }^{14} \mathrm{C}$ ethylamine treated plants, the ${ }^{14} \mathrm{C}$ activity taken up into theanine increased three-fold in leaves after 30 days incubation to as high as that in leaves after 2 days incubation (Table IV).

These results showed that the synthesized glutamine in the tea plant was immediately used as a nitrogen source and then theanine was slowly utilized after the content of glutamine or other amino acids fell in leaves. Also the reason for the accumulation of theanine in new tea shoots may be explained by this experimental result.

In ${ }^{14} \mathrm{C}$-ethylamine treated plants, some parts of ${ }^{14} \mathrm{C}$ activity were taken up into the glutamine and glutamate fractions. This is probably because a part of the ethylamine absorbed into the tea plant was transported in the tricarboxylic acid cycle through acetylCoA made by deamination of ethylamine, and reconstituted into $\alpha$-ketoglutarate, a precursor of glutamic acid, since a reasonable amount of ${ }^{14} \mathrm{CO}_{2}$ was exhausted from tea plants in the early stage after supplying with ${ }^{14} \mathrm{C}$-ethylamine.
Effect of L-methionine-DL-sulfoximine on the incorporation of ammonia into amino acids

L-Methionine-DL-sulfoximine (MSO) has been reported as an inhibitor of glutamine synthetase ${ }^{1,4)}$ and also of glutamate synthase. ${ }^{133}$

When ammonia was supplied to the roots of tea seedlings treated with MSO, the contents of amino acids and amides in the roots and leaves were depressed. Especially, the theanine content was remarkably reduced, as shown in Table V.

Table V. Contents of Amino Acids and Amides in Tea Plants Treated WITH OR WITHOUT L-METHIONINEDL-SULFOXIMINE

\begin{tabular}{lrrrrr}
\hline & \multicolumn{2}{c}{ Roots } & \multicolumn{2}{c}{ Leaves } \\
\cline { 2 - 3 } \cline { 5 - 6 } & $\begin{array}{c}\text { Treated } \\
\text { with } \\
\text { MSO }\end{array}$ & Control & $\begin{array}{c}\text { Treated } \\
\text { with } \\
\text { MSO }\end{array}$ & Control \\
\hline Total-N & 2.7 & 2.8 & 3.2 & 3.4 \\
\hline Aspartic acid & 4.8 & 11.1 & 8.7 & 19.6 \\
Threonine & 4.3 & 4.9 & 3.7 & 5.6 \\
Serine & 21.0 & 37.3 & 7.6 & 16.2 \\
Glutamic acid & 13.3 & 24.9 & 1.0 & 40.9 \\
Alanine & 15.0 & 37.4 & 6.2 & 9.9 \\
Arginine & 108.0 & 154.1 & 4.0 & 8.0 \\
Glutamine & 0.0 & 5.5 & 0.0 & 13.3 \\
Theanine & 516.4 & 836.9 & 94.9 & 125.6 \\
\hline
\end{tabular}

Total-N, \% of dry weight.

Amino acids and amides, mmol in $\mathrm{g}$ dry matter.

The activity of glutamate dehydrogenase in the rootlets was not significantly inhibited by the treatment with MSO while the activity of glutamate synthase in the rootlets was effectively inhibited, as shown in Table VI. However, the effect of MSO on the activity of glu- 
Table VI. Glutamate Dehydrogenase Activity AND Glutamate Synthase ACTIVITY IN TEA Rootlets TREATED WITH OR WITHOUT L-METHIONINE-DLSULFOXIMENE

\begin{tabular}{lcc}
\hline & $\begin{array}{c}\text { Glutamate } \\
\text { dehydrogenase }\end{array}$ & $\begin{array}{c}\text { Glutamate } \\
\text { synthase }\end{array}$ \\
\hline $\begin{array}{l}\text { Treated with MSO } \\
\text { Not treated with } \\
\text { MSO }\end{array}$ & 0.15 & 0.016 \\
\hline Activity, NADH oxidation $\mathrm{mol} / \mathrm{N} \mathrm{mg} / \mathrm{min}$.
\end{tabular}

tamine synthetase in the rootlets could not be confirmed. However, from the results of amino acid contents in tea plants treated with MSO, it was assumed that the activity of glutamine synthetase might be depressed by MSO, as shown in other plants. ${ }^{4}$ )

In this experiment, ammonia utilization in the MSO treated tea rootlets was depressed, though the glutamate dehydrogenase activity was still maintained at the same level as that in the MSO untreated tea rootlets. So it was thought that although the ammonia assimilation in tea roots was sustained by both the GS/
GOGAT system and the glutamate dehydrogenase system, the former system might be predominant in the support of the smooth ammonia type nitrogen uptake into the tea plant.

\section{REFERENCES}

1) B. J. Milfin and P. J. Lea, Phytochem., 15, 873 (1976).

2) B. J. Milfin and P. J. Lea, Ann. Rev. Plant Physiol, 28, 299 (1977).

3) I. Washitani and S. Sato, Plant Cell Physiol., 18, 505 (1977).

4) Y. Arima and K. Kumazawa, ibid, 18, 1121 (1977)

5) Y. Arima, ibid., 19, 955 (1978).

6) O. Ito, T. Yoneyama and K. Kumazawa, ibid., 19, 1109 (1978).

7) I. Washitani and S. Sato, ibid., 19, 43 (1978).

8) T. Takeo, Agric. Biol. Chem., 43, 2257 (1979).

9) T. Takeo, Phytochem., 13, 1401 (1974).

10) U. J. Kim, H. Kano and K. Kumazawa, J. Sci. Soil Manure, Jpn., 45, 600 (1975).

11) K. Kubota and N. Nakagawa, Study of tea, No. 45, 51 (1973).

12) S. H. Duke and G. H. Ham, Plant Cell Physiol., 17, 1037 (1976).

13) J. E. Brenchley, J. Bacteriol, 114, 666 (1973). 